\title{
Saccharomyces cerevisiae as a Model to Confirm the Ability of FTIR to Evaluate the Presence of Protein Aggregates
}

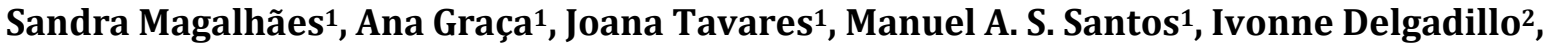 \\ Alexandra Nunes ${ }^{*}$ \\ ${ }^{1}$ iBiMED - Institute of Biomedicine, University of Aveiro, Aveiro, Portugal \\ ${ }^{2}$ QOPNA-Department of Chemistry, University of Aveiro, Aveiro, Portugal \\ Email: *alexandranunes@ua.pt
}

How to cite this paper: Magalhães, S., Graça, A., Tavares, J., Santos, M.A.S., Delgadillo, I. and Nunes, A. (2018) Saccharomyces cerevisiae as a Model to Confirm the Ability of FTIR to Evaluate the Presence of Protein Aggregates. Spectral Analysis Reviews, 6, 1-11.

https://doi.org/10.4236/sar.2018.61001

Received: September 8, 2017

Accepted: December 12, 2017

Published: December 18, 2017

Copyright $\odot 2018$ by authors and Scientific Research Publishing Inc. This work is licensed under the Creative Commons Attribution International License (CC BY 4.0).

http://creativecommons.org/licenses/by/4.0/

(c) (i) Open Access

\begin{abstract}
It is known that the presence of protein aggregates in biological samples is associated with natural aging processes and age-related diseases. The objective of this technical study was to evaluate the potential of Fourier Transform Infrared Spectroscopy to identify the presence of protein aggregates in Saccharomyces cerevisiae containing high levels of protein aggregates. We acquired ATR-FTIR spectra at mid-infrared range (between 4000 and $600 \mathrm{~cm}^{-1}$ ) and used multivariate analysis to analyze the data. Significant differences between spectra of wild type and mutant strains in the spectral range assigned to proteins were observed. In particular, an increase in $\beta$-sheet structures in mutant strains (spectral signals at 1683 and $1628 \mathrm{~cm}^{-1}$ ) was observed, indicating the putative presence of protein aggregates. These results prove the capacity of FTIR to evaluate changes in protein conformation, mainly protein aggregation, in a fast, simple and non-expensive way, producing insights on the possible application of this technique to the detection of protein aggregates in human biological samples.
\end{abstract}

\section{Keywords}

FTIR, Saccharomyces cerevisiae, Protein Aggregates, Aging

\section{Introduction}

Life expectancy has exponentially increased in the past decades, bringing huge challenges to healthcare for the treatment of age-related diseases [1] [2] [3]. In this way, it is important to promote healthy aging and so, aging biomarkers are needed to timely assess the health status of elderly people [1] [3] [4] [5]. 
The decline in proteostasis, i.e. a decrease in the activity and/or expression of the components of the unfolded protein response, is linked to the aging process [6]. This leads to the accumulation of aberrant proteins that can organize into aggregates that are potentially toxic to the cell [7]. Protein aggregates are extensively studied in the context of neurodegenerative diseases [8] [9] [10], however only few studies have so far focused on protein aggregation during natural aging [11] [12]. Therefore, specific protein aggregates not associated to a specific disease can be potential biomarkers of physiological aging. To identify these aggregates, we need reliable methodologies that can detect changes in protein conformation in biological samples in a simple, accurate and inexpensive manner. Metabolomic approaches, such as Fourier Transform Infrared Spectroscopy, seem to be reliable and promising to study protein aggregation, since age-related metabolic modifications can result in structural changes that modify IR spectra [13] [14] [15]. In order to verify the applicability of FTIR in the study of protein aggregates, one needs to use model organisms whose proteins are known to aggregate. Saccharomyces cerevisiae is a well-studied model in the context of aging and several studies have been carried out to evaluate the mechanisms involved in cellular senescence, including protein aggregation [16] [17] [18].

In this study, we have verified the applicability of FTIR to evaluate protein aggregation in $S$. cerevisiae. We have used specific mutants of $S$. cerevisiae that have the tendency to aggregate proteins at high level (unpublished). Our data clearly indicate that FTIR can be used to detect such protein aggregates.

\section{Materials and Methods}

\subsection{Yeast Strains and Growth Conditions}

We used two clones of two different strains of Saccharomyces cerevisiae derived of the BY4743 strain: a wild type strain (WT) and a mutant strain (PA) with extensive protein aggregation caused by selective knocking-out of specific RNA modification enzymes (data not published). Yeast strains were grown at $30^{\circ} \mathrm{C}$ in minimal medium without histidine (MM-His; glucose: $2 \%(\mathrm{w} / \mathrm{v})$, yeast nitrogen base without amino acids: $0.67 \%(\mathrm{w} / \mathrm{v})$, each required amino acids $(100 \mu \mathrm{g} / \mathrm{ml})$ ) (Formedium). BY4743 transformed cells were grown in MM-His and preserved at $-80^{\circ} \mathrm{C}$ in MM-His $+40 \%(\mathrm{~V} / \mathrm{V})$ glycerol. Solid media were performed by addiction of $2 \%$ agar (Formedium). All media were sterilized by heat in an autoclave.

\subsection{Determination of Protein Aggregates by Fluorescence Microscopy}

Protein aggregates were analyzed as described previously [19]. Briefly, a molecular sensor of protein aggregation was constructed by fusing the HSP104 and GFP genes under the control of the yeast HSP104 promoter. Since HSP104 is a molecular chaperone that recognizes and binds aggregated proteins the HSP104-GFP chimera permits visualizing the cellular localization of the aggre- 
gates by monitoring GFP fluorescence emission using epifluorescence or confocal microscopy.

For fluorescence microscopy analysis, cells were grown overnight and were then immobilized on $1 \%$ agarose-coated slides in order to be visualized on an Axio Imager Z1 (Zeiss) epifluorescence upright microscope using a $\times 63$ oil-immersion objective and $38 \mathrm{HE}$ GFP and Brightfield filters, and images were captured with AxionVision Software (Zeiss). Images were taken in one representative focal plane and were processed and analyzed using ImageJ

(http://rsb.info.nih.gov/ij). The presence of fluorescent foci in cells was checked and their number was manually counted. On average, 500 cells of 2 clones were analyzed.

\subsection{FTIR Spectroscopy}

MIR spectra were recorded in a Fourier transform infrared analyser (Alpha Platinum ATR, Bruker). The instrument was controlled by OPUS software (CBruker). Spectra were acquired with a resolution of $8 \mathrm{~cm}^{-1}$ with $64 \mathrm{co}$-added scans, over a wavenumber range between 4000 and $600 \mathrm{~cm}^{-1}$. Room temperature and humidity during all process were maintained stable at $23^{\circ} \mathrm{C}$ and $35 \%$, respectively. Acquisition of background single beam was performed against air (empty crystal). Yeast samples were carefully withdrawn from the culture medium with a swab and placed directly in the crystal and spectra acquisition was performed without drying. 5 replicates of each spectra were made. Diamond crystal of spectrometer was carefully cleaned with $70 \%$ ethanol and distilled water between each measurement.

\subsection{Multivariate Analysis}

Data were analyzed by principal component analysis (PCA) and partial least-squares regression analysis (PLS-R) with The Unscrambler $\mathrm{X}^{\circledast}$ software (v.10.4, Camo Software AS).

\section{Results and Discussion}

In this study Saccharomyces cerevisiae, an extensively used unicellular model [17] [20] [21] [22], was used to study protein alterations, with particular interest in PA. Wild-type and stress yeasts with induced PA were used. Figure 1 shows brightfield and fluorescence microscopy images of cells of $S$. cerevisiae, with and without protein aggregation. In WT strains cells show GFP fluorescence homogenously distributed in the whole cytoplasm, while in PA cells, fluorescence is concentrated in foci (Figure 1). Table 1 presents the percentage of cells with PA in both WT and mutant strains. WT clones have a reduced number of cells with protein aggregates. As expected, mutant strains present extensive PA.

To evaluate the potential of FTIR to detect protein aggregation, FTIR spectra of both WT and PA strains were acquired in the spectral range between 4000 and $600 \mathrm{~cm}^{-1}$. An average spectrum of both WT and PA strains is present in 

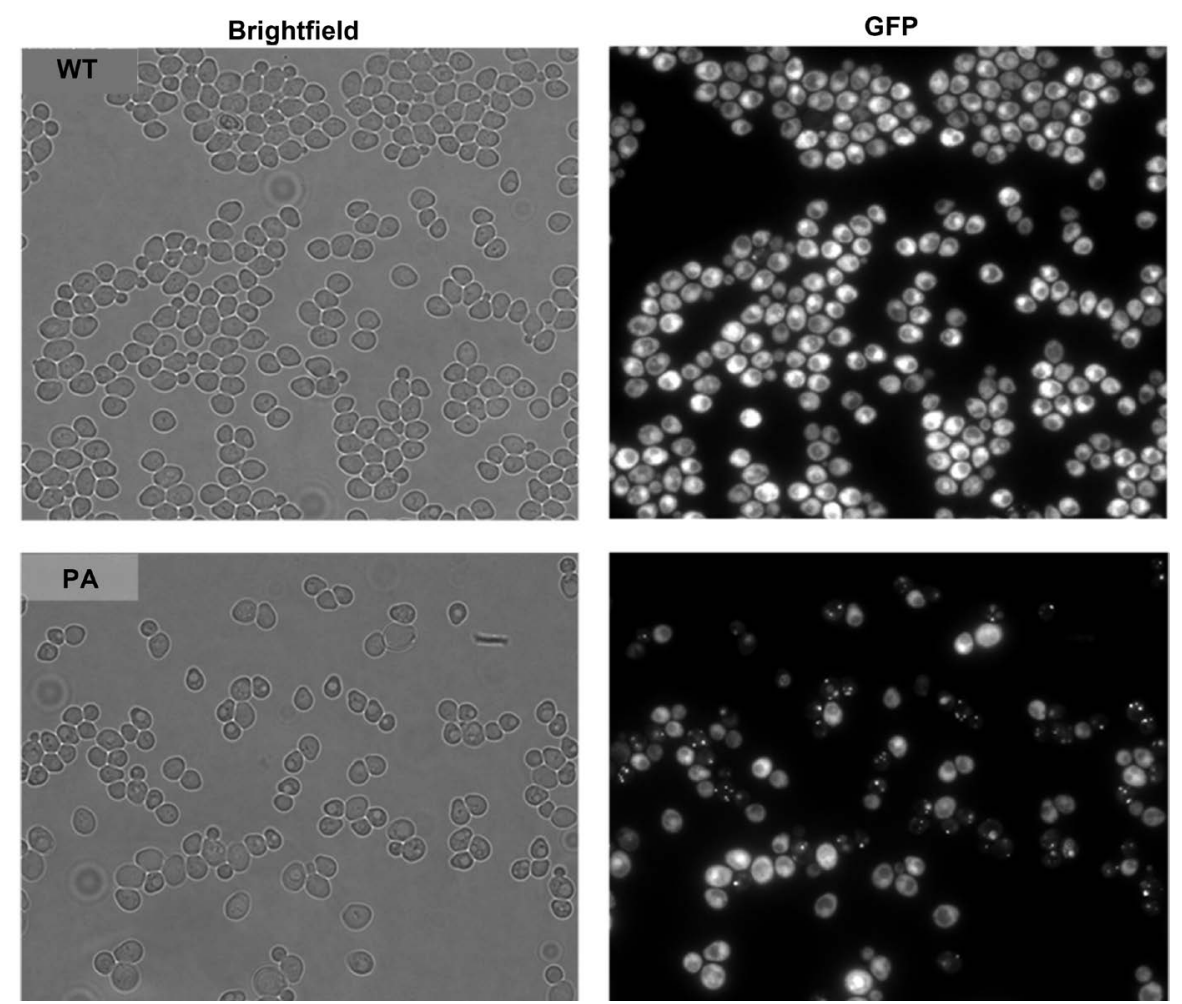

Figure 1. Wild type (WT) and mutant (PA) yeast cells expressing the Hsp104-GFP reporter protein were collected from middle exponential phase and observed by fluorescence microscopy (63× objective). Mutant cells showed localized Hsp104-GFP fluorescence, indicating the presence of protein aggregates.

Table 1. Percentage of cells with protein aggregates, measured by fluorescence microscopy. Mean and standard deviation calculated using The Unscrambler $\mathrm{X}^{\circledast}$ software (v.10.4, Camo Software AS).

\begin{tabular}{cc}
\hline Strain & Percentage of cells with protein aggregates (Mean \pm Std Deviation) \\
\hline WT Clone 1 & $1.26 \pm 0.99$ \\
WT Clone 2 & $1.18 \pm 0.68$ \\
PA Clone 1 & $56.20 \pm 25.77$ \\
PA Clone 2 & $44.79 \pm 30.78$ \\
\hline
\end{tabular}

Figure 2, with emphasis in the region between 1700 and $1500 \mathrm{~cm}^{-1}$ (Figure 2(b)), which is mainly responsible for the protein absorption (both Amide I and Amide II). Spectra were then subject to direct analysis with visualization of the spectroscopic signals related to biochemical pattern of all yeast samples. Once each spectroscopic signal is linked to a defined chemical group and/or chemical family of compounds it is possible to identify and compare the main differences between the two yeast groups. Since the spectra were obtained by directly inserting the colonies on the crystal, the dominant spectral signals were due to the water absorption and the remaining signals were underneath, so it was almost impossible to see differences between both spectra, only with direct spectra analysis. With the objective of increasing the differences between groups, 


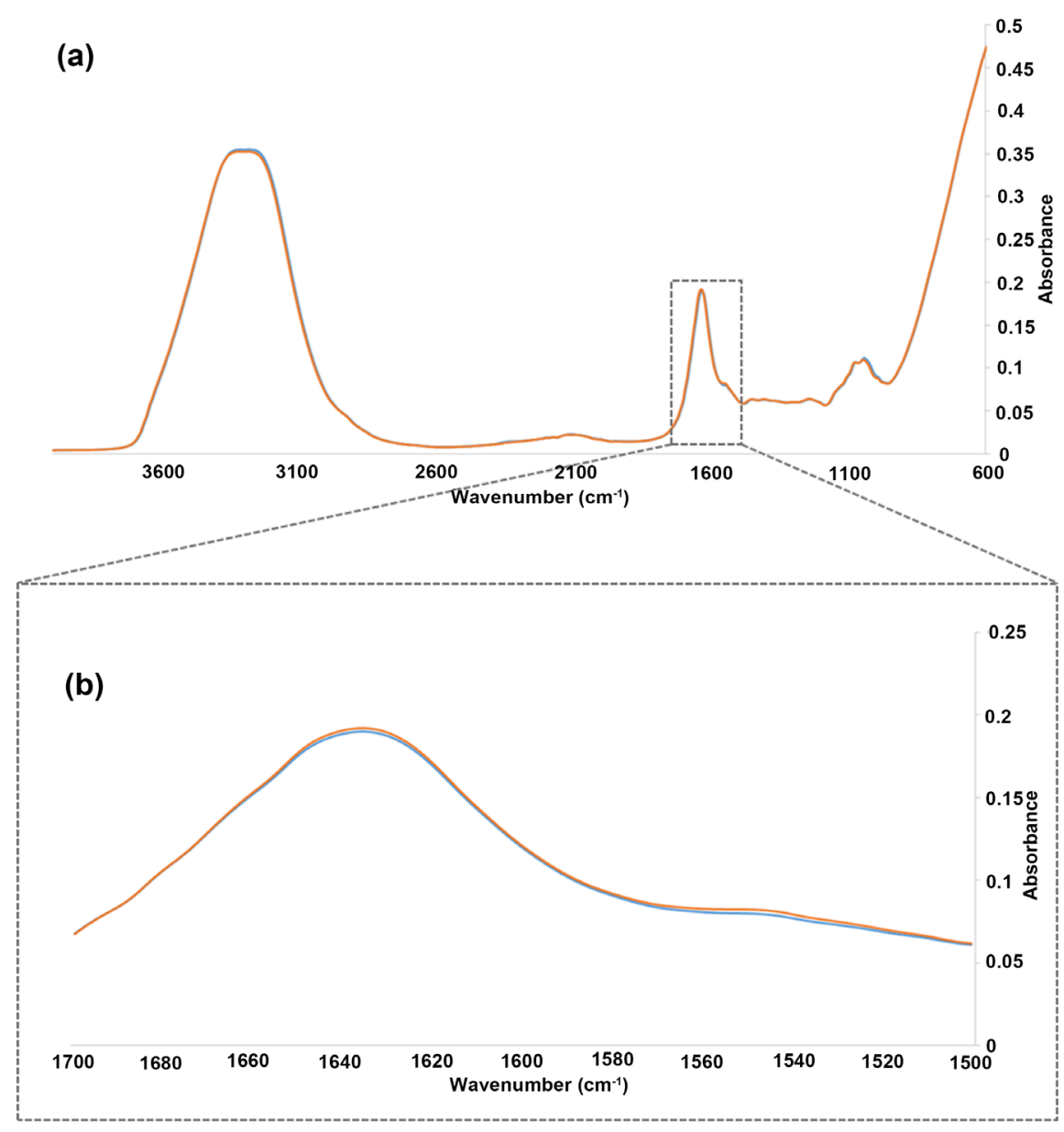

(c)

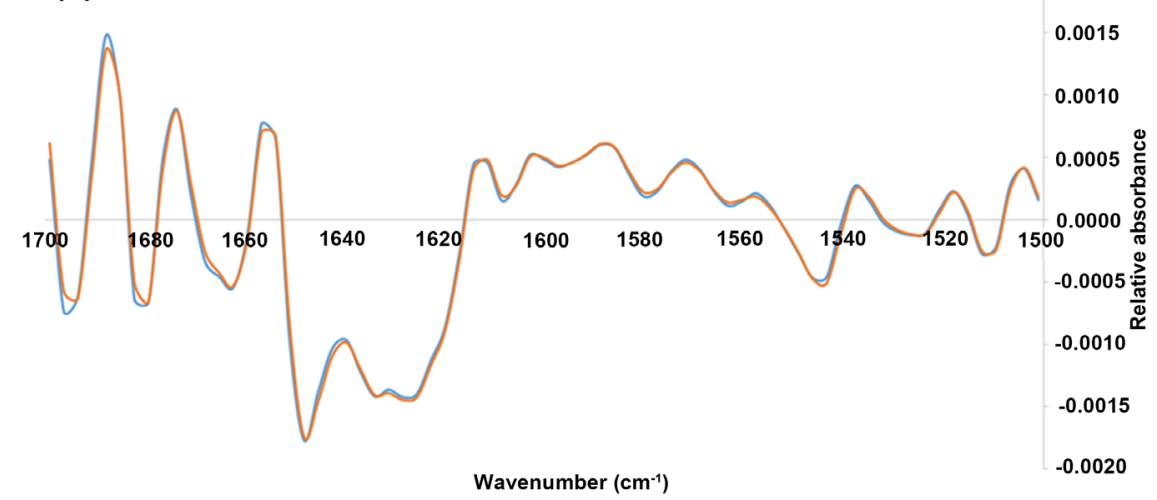

- PA - WT

Figure 2. (a) Average FTIR spectra of wild type (WT) (orange) and mutant (PA) (blue) strains of Saccharomyces cerevisiae at $4000-600 \mathrm{~cm}^{-1}$ range; (b) Amplification of protein region $\left(1700-1500 \mathrm{~cm}^{-1}\right)$ of FTIR spectra of WT and PA strains; (c) Second derivative FTIR spectra of protein region $\left(1700-1500 \mathrm{~cm}^{-1}\right)$ of WT and PA strains, processed by Savitzky-Golay algorithm. Data processed with The Unscrambler $\mathrm{X}^{\circledR}$ software (v.10.4, Camo Software AS).

$2^{\text {nd }}$ derivative processed by the Savitzky-Golay algorithm was applied to the spectra (Figure 2(c)). 
For a better comparison and characterization among the different sample groups, mainly in the protein region, principal component analysis (PCA) was applied to the $2^{\text {nd }}$ derivative spectra $\left(1700-1500 \mathrm{~cm}^{-1}\right)$ of yeast samples. PCA provides score and loading diagrams, allowing identifying and characterizing wild-type and mutant strains. $1700-1500 \mathrm{~cm}^{-1}$ spectral region allowed to observe protein alterations in the samples since it is correlated with protein secondary structure (amide I and amide II). PCA results are presented in Figure 3. We did not use PC1 and PC2 for our statistical analysis sincethese PCs represent mostly water contribution (strong signal at $\sim 1650 \mathrm{~cm}^{-1}$ ) and do not represent differences in protein conformation between samples. In score scatter plot
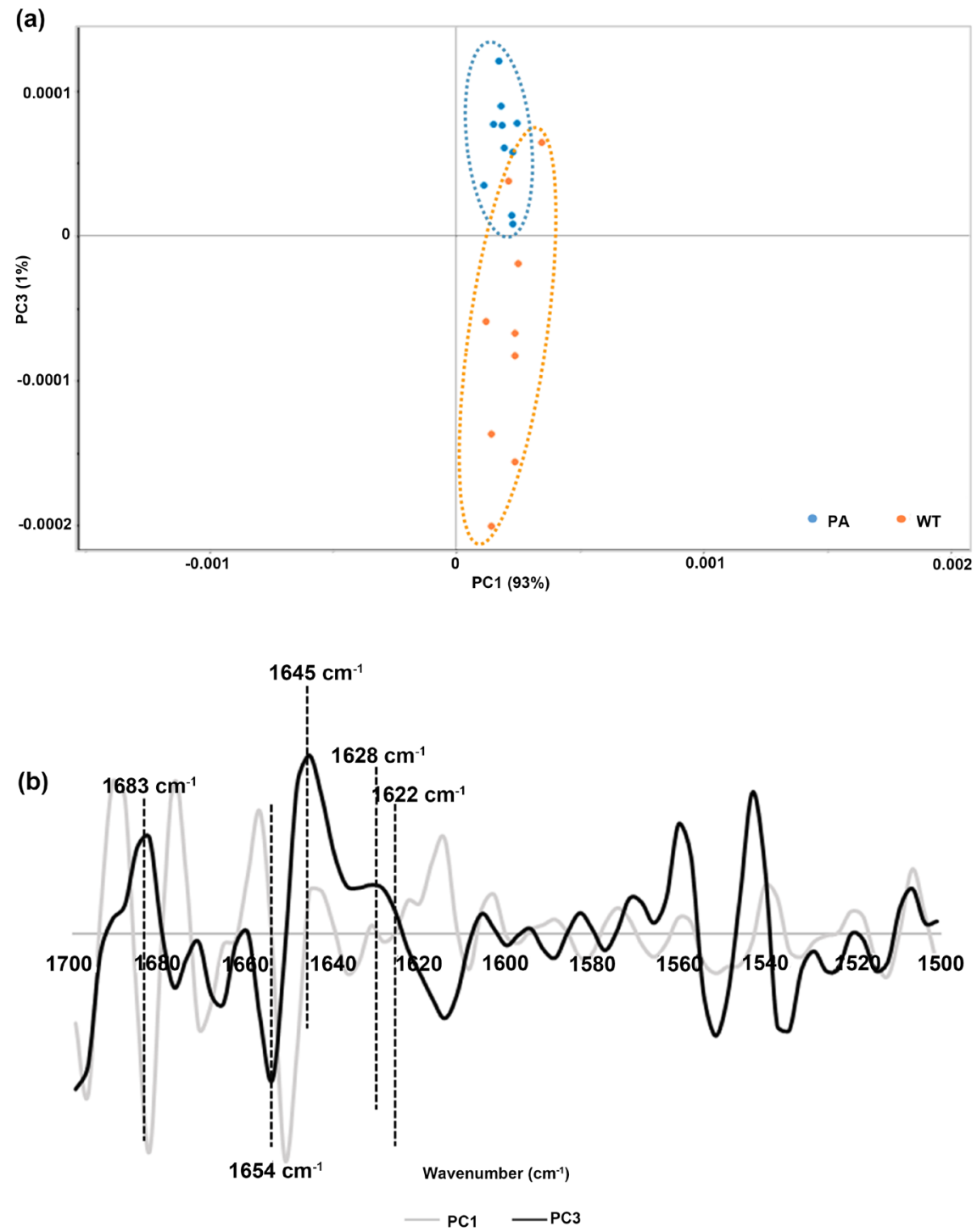

Figure 3. Principal Component Analysis (PCA) score plot (a) and loading plot (b) from 2nd derivative spectra of WT and PA strains on the protein region $\left(1700-1500 \mathrm{~cm}^{-1}\right)$. Changes from each group were discriminated by PC1 vs PC3 score plot. PC1 and PC3 explained a respective $93 \%$ and $1 \%$ of the total variance. Data processed with The Unscrambler $\mathrm{X}^{\circledast}$ software (v.10.4, Camo Software AS). 


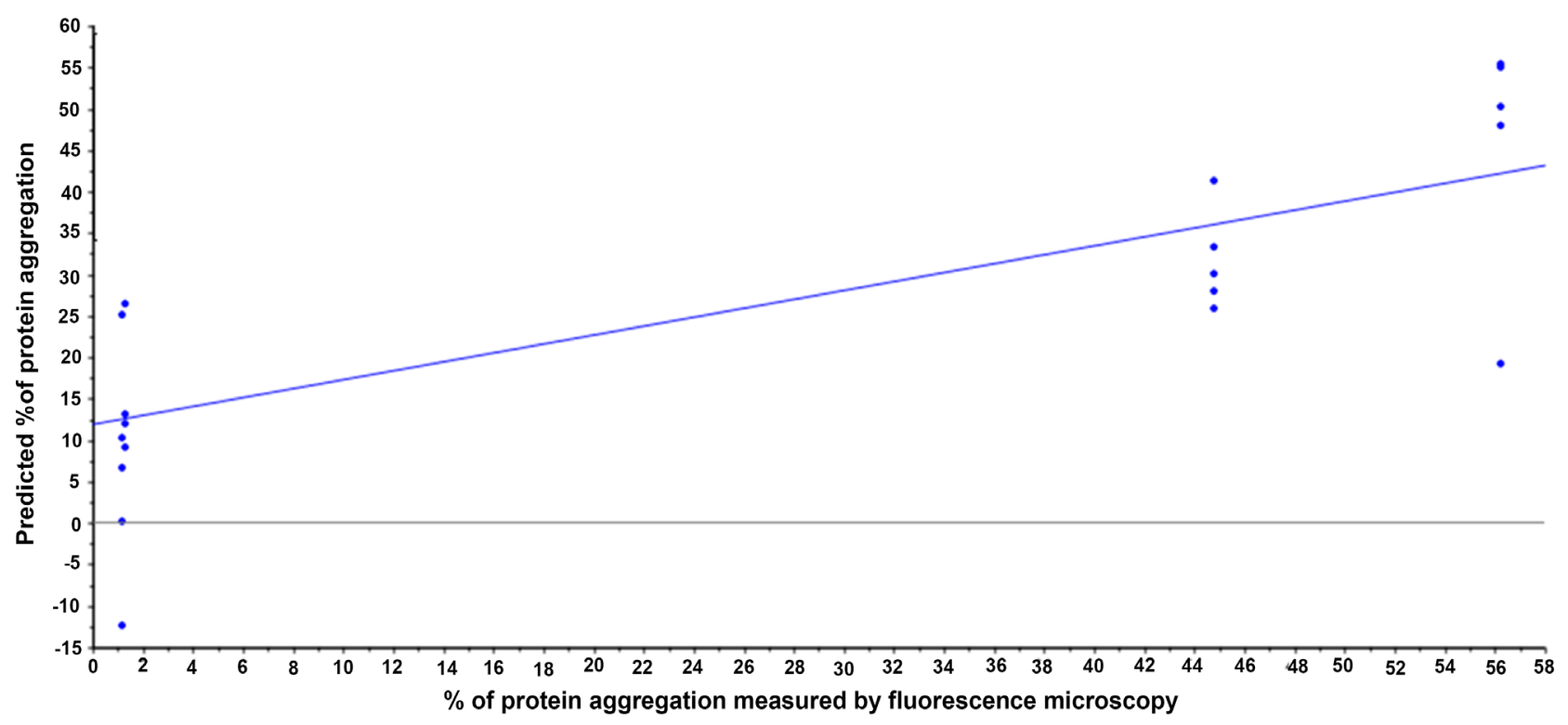

(a)

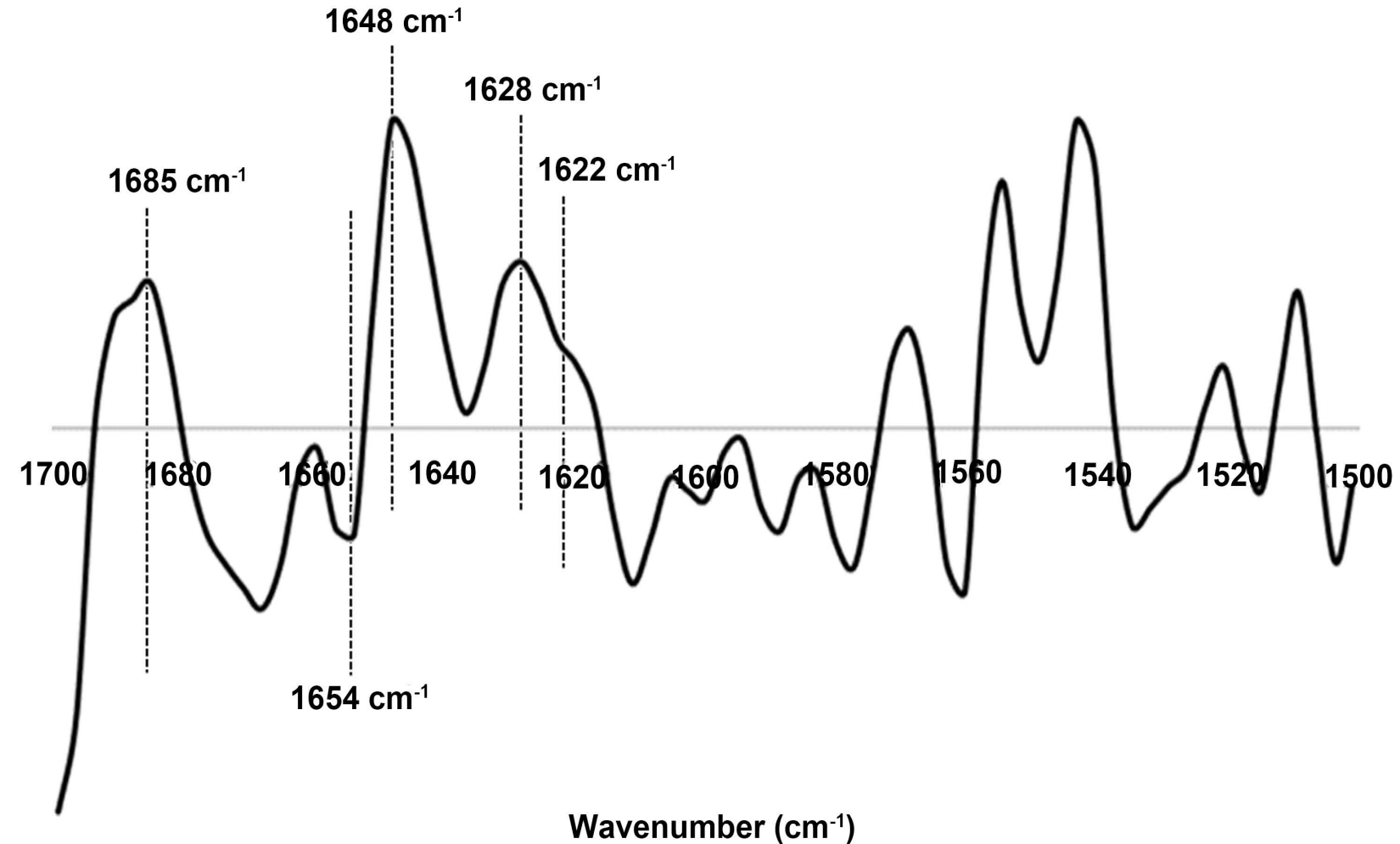

(b)

Figure 4. (a) Partial Least Squares Regression of 2nd derivative spectra on the protein region (1700 - $\left.1500 \mathrm{~cm}^{-1}\right)$ of WT and PA strains, using two latent variables. $y=0.5385154 \mathrm{x}+11.932844, \mathrm{R} 2=0.5385148, \mathrm{RMSEC}=16.9598$ and RMSEP $=20.6460$; (b) PLS B-coefficients of factor 2 of 2 nd derivative spectra on the protein region $\left(1700-1500 \mathrm{~cm}^{-1}\right)$ of WT and PA strains. Data processed with The Unscrambler $\mathrm{X}^{\circledR}$ software (v.10.4, Camo Software AS).

(Figure 3(a)) it is possible observe that the wild-type (WT) samples are located mainly in negative PC3 and the stress (PA) samples are mainly in positive PC3 
region. PCA loadings allow the comprehension of the distributional pattern of the samples (Figure 3(b)) and the identification of molecular alterations that might be present. PA samples are characterized by spectroscopic signals located at $1683,1645,1628$ and $1622 \mathrm{~cm}^{-1}$ and WT samples are characterized by the peak at $1654 \mathrm{~cm}^{-1}$. To understand this discrimination, it is essential to assign these peaks to the corresponding biological contributor. In accordance to literature, the peak at $1654 \mathrm{~cm}^{-1}$, here related to WT strains, is associated to $\alpha$-helix structures in proteins [23] [24] [25] [26], which are usually present in more soluble structures and so less prone to aggregate. Conversely, peaks at $1683 \mathrm{~cm}^{-1}$ and $1628 \mathrm{~cm}^{-1}$, associated with mutant strains, are related to $\beta$-sheet structures in fungal proteins [26] [27]. It is important to notice that $\beta$-sheet structures are usually related with less soluble and more prone to aggregate proteins, so these peaks could be directly related with the presence of PA in mutant strains, corroborating microscopy results. Also, the peak at $1622 \mathrm{~cm}^{-1}$ is assigned to a shift in amide I bands, commonly related with the presence of protein aggregates [13] [26] [28]. The peak at $1645 \mathrm{~cm}^{-1}$ is related to $\beta$-turns structures in amide I band of proteins [23] [26] [29] [30] [31].

A PLS analysis was also applied to the $2^{\text {nd }}$ derivative spectra $\left(1700-1500 \mathrm{~cm}^{-1}\right.$ spectral region) to explore the correlation between the spectra profile and percentage of protein aggregation evaluated by fluorescence microscopy in the yeasts samples. A calibration model with two latent variables was built $(\mathrm{y}=$ $0.5385154 \mathrm{x}+11.932844$ ) with a $\mathrm{R}^{2}$ of 0.5385148 , a RMSEC of $16.96 \%$ and of RMSEP of $20.6 \%$ (Figure 4(a)). The PLS B-coefficient built with factor 2 showed that $1685,1645,1628$ and $1622 \mathrm{~cm}^{-1}$ are positively correlated with the samples with higher amounts of protein aggregation (Figure 4(b)). The relation between the PA samples and these spectroscopic signals, related with the presence of $\beta$-sheet structures and protein aggregates, corroborate the PCA results confirming that it is possible to evaluate the presence of protein aggregation by FTIR spectroscopy.

One of the drawbacks of this study is the fact that we did not determine the exact number of cells placed in ATR crystal. We used a $10 \mu \mathrm{L}$ swab for all samples, however it is impossible to be completely certain that the number of cells was the same in each measurement.

These data confirm that FTIR has the potential to identify changes in protein conformation, possibly related with the presence of protein aggregates in a eukaryotic model. The fact that FTIR is a fast, non-destructive, simple and inexpensive metabolomic analysis makes it of particular interest to the study of biological samples. In fact, in the future, we intend to apply FTIR to study mice tissue samples and to determine the pattern of protein aggregation during aging in mammals and ultimately identify new aging biomarkers.

\section{Conflict of Interest}

The Authors declare that there is no conflict of interest. 


\section{Funding}

This work was supported by iBiMED - Institute of Biomedicine, University of Aveiro and the Fundação para a Ciência e Tecnologia of the Ministry of Education and Science of Portugal [grants number UID/BIM/04501/2014; BI/UI98/ 7395/2016 to S.M. and SFRH/BD/86866/2012 to J.T.].

\section{References}

[1] Kirklanda, J.L. (2013) Translating Advances from the Basic Biology of Aging into Clinical Application. Experimental Gerontology, 48, 1-5. https://doi.org/10.1016/j.exger.2012.11.014

[2] WHO. Ageing and Health. http://www.who.int/mediacentre/factsheets/fs404/en/

[3] American Federation for Aging Research (AFAR) (2011) Infoaging Guide to Biomarkers of Aging.

[4] Davinelli, S., Caruso, C., Zella, D., Scapagnini, G. and Vasto, S. (2012) Molecular Biomarkers of Aging. INTECH Open Access Publisher. https://doi.org/10.5772/32944

[5] Ellis, D.I., Dunn, W.B., Griffin, J.L., Allwood, J.W. and Goodacre, R. (2007) Metabolic Fingerprinting as a Diagnostic Tool. Pharmacogenomics, 8, 1243-1266. https://doi.org/10.2217/14622416.8.9.1243

[6] López-Otín, C., Blasco, M.A., Partridge, L., Serrano, M. and Kroemer, G. (2016) The Hallmarks of Aging. Cell, 153, 1194-1217. https://doi.org/10.1016/j.cell.2013.05.039

[7] Kaushik, S. and Cuervo, A.M. (2015) Proteostasis and Aging. Nature Medicine, 21, 1406-1415. https://doi.org/10.1038/nm.4001

[8] Forloni, G., Artuso, V., La Vitola, P. and Balducci, C. (2016) Oligomeropathies and Pathogenesis of Alzheimer and Parkinson's Diseases. Movement Disorders, 31, 771-781. https://doi.org/10.1002/mds.26624

[9] Kopito, R.R. and Ron, R. (2016) Kopito: Unfolding the Secrets of Protein Aggregation. Trends Cell Biol. https://doi.org/10.1016/j.tcb.2016.05.001

[10] Ludtmann, M.H.R. and Abramov, A.Y. (2016) Protein Misfolding and Aggregation: Implications for Mitochondrial Dysfunction and Neurodegeneration. In: Mitochondrial Dysfunction in Neurodegenerative Disorders; Springer, 241-253. https://doi.org/10.1007/978-3-319-28637-2_10

[11] Walther, D.M., Kasturi, P., Zheng, M., Pinkert, S., Vecchi, G., Ciryam, P., Morimoto, R.I., Dobson, C.M., Vendruscolo, M., Mann, M. and Hartl, F.U. (2015) Widespread Proteome Remodeling and Aggregation in Aging C. Elegans. Cell, 161, 919-932. https://doi.org/10.1016/j.cell.2015.03.032

[12] Xia, K., Trasatti, H., Wymer, J.P. and Colón, W. (2016) Increased Levels of Hyper-Stable Protein Aggregates in Plasma of Older Adults. Age (Omaha), 38, 1-9. https://doi.org/10.1007/s11357-016-9919-9

[13] Miller, L.M., Bourassa, M.W. and Smith, R.J. (2013) FTIR Spectroscopic Imaging of Protein Aggregation in Living Cells. Biochimica et Biophysica Acta, 1828, 2339-2346.

[14] Shivu, B., Seshadri, S., Li, J., Oberg, K.A., Uversky, V.N. and Fink, A.L. (2013) Distinct $\beta$-Sheet Structure in Protein Aggregates Determined by ATR-FTIR Spectroscopy. Biochemistry, 52, 5176-5183. https://doi.org/10.1021/bi400625v

[15] Baker, M.J., Trevisan, J., Bassan, P., Bhargava, R., Butler, H.J., Dorling, K.M., Fiel- 
den, P.R., Fogarty, S.W., Fullwood, N.J., Heys, K.A., Hughes, C., Lasch, P., Martin-Hirsch, P.L., Obinaju, B., Sockalingum, G.D., Sulé-Suso, J., Strong, R.J., Walsh, M.J., Wood, B.R., Gardner, P. and Martin, F.L. (2014) Using Fourier Transform IR Spectroscopy to Analyze Biological Materials. Nature Protocols, 9, 1771-1791. https://doi.org/10.1038/nprot.2014.110

[16] Winkler, J., Tyedmers, J., Bukau, B. and Mogk, A. (2012) Chaperone Networks in Protein Disaggregation and Prion Propagation. Journal of Structural Biology, 179, 152-160. https://doi.org/10.1016/j.jsb.2012.05.002

[17] Denoth Lippuner, A., Julou, T. and Barral, Y. (2014) Budding Yeast as a Model Organism to Study the Effects of Age. FEMS Microbiology Reviews, 38, 300-325. https://doi.org/10.1111/1574-6976.12060

[18] Zhou, C., Slaughter, B.D., Unruh, J.R., Eldakak, A., Rubinstein, B. and Li, R. (2011) Motility and Segregation of Hsp104-Associated Protein Aggregates in Budding Yeast. Cell, 147, 1186-1196. https://doi.org/10.1016/j.cell.2011.11.002

[19] Erjavec, N., Larsson, L., Grantham, J. and Nyström, T. (2007) Accelerated Aging and Failure to Segregate Damaged Proteins in Sir2 Mutants Can Be Suppressed by Overproducing the Protein Aggregation-Remodeling Factor Hsp104p. Genes \& Development, 21, 2410-2421. https://doi.org/10.1101/gad.439307

[20] Kaeberlein, M., Burtner, C.R. and Kennedy, B.K. (2007) Recent Developments in Yeast Aging. PLOS Genetics, 3, 655-660.

https://doi.org/10.1371/journal.pgen.0030084

[21] Magalhães, J.P. Human Aging Model Systems.

[22] Steinkraus, K.A., Kaeberlein, M. and Kennedy, B.K. (2008) Replicative Aging in Yeast: The Means to the End. Annual Review of Cell and Developmental Biology, 24, 29-54. https://doi.org/10.1146/annurev.cellbio.23.090506.123509

[23] Yu, C. and Irudayaraj, J. (2005) Spectroscopic Characterization of Microorganisms by Fourier Transform Infrared Microspectroscopy. Biopolymers, 77, 368-377. https://doi.org/10.1002/bip.20247

[24] Tang, M., McEwen, G.D., Wu, Y., Miller, C.D. and Zhou, A. (2013) Characterization and Analysis of Mycobacteria and Gram-Negative Bacteria and Co-Culture Mixtures by Raman Microspectroscopy, FTIR, and Atomic Force Microscopy. Analytical and Bioanalytical Chemistry, 405, 1577-1591. https://doi.org/10.1007/s00216-012-6556-8

[25] Beekes, M., Lasch, P. and Naumann, D. (2007) Analytical Applications of Fourier Transform-Infrared (FT-IR) Spectroscopy in Microbiology and Prion Research. Veterinary Microbiology, 123, 305-319. https://doi.org/10.1016/j.vetmic.2007.04.010

[26] Magalhães, S. and Nunes, A. (2017) Fourier Transform Infrared Spectroscopy Applied to the Study of Unicellular Models. Current Metabolomics, 5.

[27] Barth, A. and Zscherp, C. (2002) What Vibrations Tell about Proteins. Quarterly Reviews of Biophysics, 35, 369-430. https://doi.org/10.1017/S0033583502003815

[28] Miller, L.M., Wang, Q., Telivala, T.P., Smith, R.J., Lanzirotti, A. and Miklossy, J. (2006) Synchrotron-Based Infrared And X-Ray Imaging Shows Focalized Accumulation of $\mathrm{Cu}$ And $\mathrm{Zn}$ Co-Localized With $\beta$-Amyloid Deposits in Alzheimer's Disease. Journal of Structural Biology, 155, 30-37. https://doi.org/10.1016/j.jsb.2005.09.004

[29] Jiang, W., Saxena, A., Song, B., Ward, B.B., Beveridge, T.J. and Myneni, S.C.B. (2004) Elucidation of Functional Groups on Gram-Positive and Gram-Negative 
Bacterial Surfaces using Infrared Spectroscopy. Langmuir, 20, 11433-11442.

[30] Kardas, M., Gozen, A.G. and Severcan, F. (2014) FTIR Spectroscopy Offers Hints towards Widespread Molecular Changes in Cobalt-Acclimated Freshwater Bacteria. Aquatic Toxicology, 155, 15-23. https://doi.org/10.1016/j.aquatox.2014.05.027

[31] Naumann, D. (2001) FT-Infrared and FT-Raman Spectroscopy in Biomedical Research. Applied Spectroscopy Reviews, 36, 239-298.

https://doi.org/10.1081/ASR-100106157 